\title{
Hacia un cambio en el sector de moda y lujo. Del dominio del influencer a la marca: Gucci, Loewe y Margiela
}

\author{
Towards a change in the fashion and luxury sector. From \\ the domain of the influencer to the brand: Gucci, Loewe and \\ Margiela
}

\author{
Sanz Marcos, P., Pérez Curiel, C. y Velasco Molpeceres, A. M. ${ }^{1}$ \\ Recibido: 14-04-2020 - Aceptado: 20-08-2020 \\ https://doi.org/10.26441/RC19.2-2020-A15
}

\begin{abstract}
RESUMEN: El influencer, considerado como un activo clave en la estrategia para la comunicación online (Pérez-Curiel y Clavijo-Ferreira, 2017), provoca una pérdida del control sobre las decisiones estratégicas de las marcas de moda debido a su independencia a la hora de desarrollar acciones (Díaz, 2017). Con objeto de describir en qué medida el influencer potencia la identidad de marca y la tendencia de cambio de estrategia en el sector, se diseña una metodología de análisis de contenido comparado de triple enfoque (Silverman, 2016; Krippendorff, 2004) que analiza las cuentas de Instagram de tres firmas de lujo de referencia internacional como Gucci, Loewe y Margiela (posts totales n1= 3756 y específicos $n 2=240$ ) y desarrolla un panel de expertos $(n 3=6)$ dirigido a profesionales y académicos especializados. Los resultados indican cómo se ven afectados los valores e imagen corporativa de las marcas debido al discurso egopersonal de estos perfiles de influencia.
\end{abstract}

Palabras Clave: branding; influencer; Instagram; comunicación corporativa; identidad de marca; marcas de lujo.

ABSTRACT: The influencer, considered a key asset in the strategy for online communication (Pérez-Curiel and Clavijo-Ferreira, 2017), causes a loss of control over the strategic decisions of fashion brands due to their independence in developing actions (Díaz, 2017). In order to describe to what extent, the influencer enhances the brand identity and the change in strategy trend in the sector, a triple-focus comparative content analysis methodology is designed (Silverman, 2016; Krippendorff, 2004). It analyzes the Instagram accounts of three international renowned luxury firms such as Gucci, Loewe and Margiela (total posts $n 1=3756$ and specific posts $n 2=240$ ) and develops a panel of experts $(n 3=6)$ aimed at specialized professionals and academics. The results indicate how the values and corporate image of the brands are affected by the ego-personal discourse of these influence profiles.

Keywords: branding; influencer; Instagram; corporate communication; brand identity; luxury brands.

\footnotetext{
${ }_{1}^{1}$ Paloma Sanz Marcos es Doctora en Comunicación por la Universidad de Sevilla y profesora de Marketing y publicidad en Departamento de Comunicación Audiovisual y Publicidad de la Facultad de Comunicación de la Universidad de Cádiz. palomasanz@us.es, https://orcid.org/0000-0002-6103-6993

Concha Pérez Curiel es Doctora en Periodismo por la Universidad de Sevilla, profesora en la Facultad de periodismo y directora del Máster de moda y comunicación en la misma universidad. cperez1 @us.es, https://orcid. org/0000-0002-1888-0451

Ana María Velasco Molpeceres es Doctora en Comunicación por la Universidad de Valladolid y profesora de Historia económica y comunicación en la Facultad de Ciencias Económicas y Empresariales de la misma universidad. anamaria.velasco.molpeceres@uva.es, http://orcid.org/0000-0002-0593-0325
} 


\section{Introducción}

La consideración de las redes sociales como complemento de las estrategias de comunicación convencionales de las marcas de moda se presenta ya como axioma y valor intrínseco dentro del plan de acción publicitaria y de marketing empresarial. El uso de las plataformas que permiten dar visibilidad a las marcas en el medio online es actualmente una tendencia que los denominados prosumers (productores y consumidores en la red) perciben de manera natural (Monserrat-Gauchi y Sabater-Quinto 2017). El sector de moda y lujo no permanece al margen y se integra en un proceso activo, sin renunciar a los valores consustanciales de precio, calidad y exclusividad (Bastien y Kapferer, 2012), abogando por la presencia en las redes sociales (Kim \& Ko, 2012; Phan, Thomas, \& Heine, 2011). En el caso concreto de las marcas de lujo se hace especialmente notable la necesidad de buscar nuevas estrategias que animen a la interacción con sus públicos. Su consumo implica una serie de ventajas sociales que permiten a los consumidores alcanzar un determinado status social y la obtención de una serie de beneficios psicológicos (Shukla, 2011). Sin embargo, la relación de utilidad intangible y situacional en relación al precio es alta (Vickers \& Renand, 2003), es por ello que el sector se encuentra en constante desafío. Marcas como Gucci, Loewe y Margiela consideradas como referentes del sector (Ranking BrandZ de Milldward Brown, 2015; ClikZ Digital News, 2015) y líderes en el mercado, hacen uso del storytelling para llegar de forma emocional a sus clientes, y transmitirles la esencia, identidad, historia y valores de la marca (González Romo y Plaza Romero, 2017). Una de las prácticas más reconocidas en el escenario de las plataformas digitales es la colaboración con el influencer, estratega y productor de contenidos que domina la comunicación online (Pérez-Curiel y Clavijo-Ferreira, 2017). En general, cuentan con una reputación digital referente que, como expertos en una materia, publican contenidos que son leídos por miles de seguidores y generan una comunidad (Pedroni 2016), con elevadas tasas de interacción y engagement, promovido por las propias marcas para motivar, potenciar y medir las contribuciones de los clientes a las funciones de marketing (Castelló-Martínez, 2016; Harmeling, Moffett, Arnolf y Carlson, 2017).

Según el Diccionario LID Marketing directo e interactivo (Van Nispen, 2015), los influencers son personas que utilizan las redes sociales para generar información sobre productos y servicios de cualquier tema de actualidad. Comparten con otros usuarios sus opiniones, pensamientos, ideas o reflexiones. En la misma línea la Word of Mouth Marketing Association define al influencer como «aquella persona que identifica, busca y se adapta con influencia a cualquier objetivo empresarial» (WOMMA, 2017).

Investigaciones previas (Vinader Segura, Vicente Fernández y Gallego Trijueque, 2019; Segarra-Saavedra e Hidalgo-Marí, 2018; Sádaba y San Miguel, 2016) desatacan el papel del influencer como protagonista de las acciones comunicativas de las marcas de moda y lujo. Sin embargo, debido a su condición ajena con respecto a la organización con la que colabora, el influencer alcanza una capacidad de decisión que supera el control de la propia marca, generando en ocasiones un conflicto de intereses (Sanz-Marcos, Jiménez-Marín y Elías-Zambrano, 2019).

$\mathrm{Y}$ es en este contexto donde Instagram y sus seguidores, imbuidos por el poder de la imagen, se postulan como ejes de dinamización y viralización del mensaje de marca, (Ramos-Serrano y Martínez-García, 2016) y herramienta viral de un director de orquesta - el influencer - con una repuesta no proporcional a la de su comunidad de fans (De Veirman, Cauberghe y Hudders, 2017).

\subsection{Redes de influencia y nuevos modelos de consumo en moda}

Actualmente la moda es más fluida e interactiva que nunca, cambiando la forma en la que las marcas se conectan con su audiencia principal. Su dinámica viene determinada por un nuevo perfil de 
consumidores, los millennials, con un enorme potencial para el desarrollo de acciones de comunicación y de marketing (Martínez-Sala et al., 2018; Pérez Curiel y Luque Ortiz, 2018; Ruiz Cartagena, 2017; Beauchamp y Barnes, 2015).

En este escenario surge un nuevo modo de consumo en el que los usuarios de las redes sociales actúan como adprosumers, generando contenido, interactuando con la marca y anunciando su experiencia para informar a otros consumidores (Ferrer González, 2018). Se cre, pues, un protocolo de seducción ponderado por la figura del influencer, que se convierten en embajadores de marca dado que aportan credibilidad ante los ojos del consumidor.

La Interactive Advertising Bureau (IAB) recoge en el primer Libro Blanco de Marketing de Influencers, elaborado con la comisión de Influencers de IAB Spain que, el 72\% de los internautas sigue a algún influencer a través de sus redes sociales y el 55\% afirma que influyen en su decisión de compra. Asimismo, el informe anual publicado por Launchmetrics (2019) sobre marketing de influencers en el sector de la moda, la belleza y el lujo, pone de relieve la relevancia de perfiles como el de la influencer Chiara Ferragni para generar engagement entre el público y la marca.

Decidir con qué influencer trabajar y hacia qué público objetivo dirigirse es fundamental, sobre todo porque los propios influencers pueden ser un arma de doble filo para las marcas y generar mayor atracción sobre sus publicaciones, infravalorando las estrategias de la empresa (Díaz, 2017). Las marcas deben discernir sobre la elección entre macroinfluencers o microinfluencers, que, aun siendo más desconocidos, generan mayor atracción sobre el producto. Sobre estos argumentos surge el desmentido acerca de la influencia, la popularidad o el número de seguidores como garantes del éxito de la comunicación en las redes. Según el estudio Instagram Marketing: Does Influencer Size Matter? a medida que el número de seguidores de un influencer aumenta, la tasa de compromiso (likes y comentarios) de ese influencer disminuye (Markely, 2017).

\subsection{El branding de influencia. Claves comunicativas sobre identidad y audiencia}

Uno de los reflejos más significativos del cambio que las redes sociales han suscitado en el escenario en el que las marcas se comunican con sus públicos (Khan, 2018), afecta a la percepción de los consumidores. Este proceso de democratización de la moda, sin desestimar la perduración de las marcas de lujo como emblema del sector, produce nuevas tendencias y roles, provocando un cambio de comportamiento para encajar en la fast-fashion y en las peculiaridades del mundo digital y la compra online. El marketing digital se posiciona como estrategia a través de la cual las redes sociales se consideran espacios publicitarios en los que los usuarios se erigen como líderes de opinión o prescriptores, logrando llegar a un mayor número de consumidores potenciales (Castelló-Martínez y Del-Pino-Romero, 2015).

El control tradicional que las empresas ejercen sobre la imagen de sus marcas se encuentra en un constante desafío debido a los nuevos patrones y exigencias de este nuevo medio de difusión (Martínez Navarro, 2018). Bajo este paradigma, las comunicaciones corporativas no se encuentran de manera exclusiva controladas por las organizaciones, por el contrario, el desempeño que estos influencers ejercen puede llegar a provocar interpretaciones equívocas en la mente de los consumidores. Como prescriptores de marca, basan sus estrategias en los consejos que lanzan a sus seguidores. En el caso de las marcas de moda, suelen ser percibidas en la mente de los consumidores con asociaciones cercanas a cuestiones como la calidad, la estética o lo extraordinario (Pedri Pereira y Schneider, 2017).

La complejidad dibuja un escenario de interacción usuario/marca en las redes en el que lo fundamental es establecer relaciones a través de un vínculo emocional compartido por la comunidad (Tsai, Huang y Chiu, 2012). Se dibuja pues un nuevo mapa digital en el que quizás las marcas acepten el reto de convertirse en influencers de sus propias redes, garantizando una comunicación 
focalizada en la promoción del producto y en la respuesta directa y bidireccional hacia los seguidores afines y potenciales de Instagram.

\section{Objetivos, hipótesis y preguntas de investigación}

Este estudio plantea una serie de objetivos a partir de los cuales se pretende avanzar en la localización de nuevas tendencias, roles, funciones y relaciones entre los protagonistas del discurso digital de la moda, en los nuevos modelos de mercado potenciados por las marcas, en la valoración de las empresas y de las audiencias sobre el perfil influencer y, en definitiva, en la repercusión social vinculada a las nuevas narrativas de la comunicación y el marketing de moda en red.

Los objetivos $(\mathrm{O})$ se concretan de la siguiente manera:

O1. Conocer qué estrategias proyectan las marcas de moda y los influencers para promocionar la imagen del producto en Instagram, analizando en qué medida la imagen y el mensaje del influencer potencian la identidad de marca.

O2. Comprobar el nivel de interacción y engagement de la marca de moda con el influencer y con los usuarios, como prosumers en Instagram.

O3. Definir la tendencia en el posicionamiento y la difusión del producto desde la perspectiva empresarial de la industria de la moda frente al modelo actual de comunicación centralizado en la colaboración con el influencer.

En relación a estos objetivos, se plantean las siguientes preguntas de investigación (PI):

P1. ¿Qué estrategias definen la actuación de las marcas de moda para reforzar su identidad ante la figura del influencer y ante los consumidores?

P2. ¿Cómo se relacionan la marca de moda y el influencer en la red Instagram? ¿Cómo es esta interacción en relación a los prosumers?

P3. ¿Se puede hablar de una nueva tendencia en la que prevalece el protagonismo de la identidad de la marca de moda por delante del rol que hasta ahora han desempeñado los influencers?

Como complemento a las anteriores preguntas de investigación, se establece asimismo una hipótesis $(\mathrm{H})$ que el análisis empírico de este trabajo propone resolver.

H1. La nueva tendencia de comunicación en moda defiende un modelo de estrategia que potencia la identidad de la marca y el rol del usuario, redefiniendo el papel del influencer, hasta ahora considerado imagen dominante en la red.

Según esta premisa, se considera que la influencia, centralizada en un protagonista único, pasa a ser compartida e incluso sustituida por el interés de la empresa por controlar el producto y decidir las vías para la difusión y venta. Una tendencia que se ve reforzada por la confianza que las marcas depositan en los consumidores digitales. Asistimos pues, a un debate abierto sobre los efectos de la imagen del influencer en la identidad de marca, sobre la interactividad con los usuarios de la red y sobre la posible innovación comunicativa de las empresas de moda, regidas por principios holísticos generales de producción y consumo.

\section{Metodología}

El método propuesto se apoya en una serie de investigaciones previas basadas, en el análisis de contenido comparado de indicadores cuantitativos y cualitativos (Silverman, 2016; Bryman, 2016; 
Franklin et. al, 2015; Krippendorff, 2004; Flick, 2004), así como en el diseño de un panel de expertos (Gideon, 2012; Finch y Lewis, 2003), integrado por profesionales del sector e investigadores del ámbito de la comunicación y la moda. Ambos procesos constituyen la base científica de comprobación de la hipótesis general del estudio.

\subsection{Indicadores de Contexto}

A partir del seguimiento de las cuentas digitales de tres marcas internacionales de moda y lujo como Gucci (@gucci),Loewe (@loewe) y Margiela (@maisonmargiela),pertenecientes a tres holdings de referencia como Kering, LVMH y OTB se analiza, por una parte, la función de los influencers, la temática de sus posts y el grado de acción e interacción con los usuarios y las marcas. Estos indicadores de contexto se vinculan con el objetivo $\mathrm{O} 1$ y $\mathrm{O} 2$ en tanto que proporcionan información acerca del tipo de estrategias proyectadas por las marcas de moda así como su conexión con los influencers y usuarios.

Por otra parte, y en consonancia con el objetivo O3, desde la perspectiva de la industria y desde la óptica de los expertos en comunicación y moda, se describen las nuevas líneas estratégicas de las marcas seleccionadas, que, comparten una dinámica común, centrada en posicionar el producto y en revitalizar la relación con el cliente, como potencial consumidor.

En esta línea, diseñamos una metodología de análisis de contenido cuantitativo y cualitativo de enfoque comparado (aplicado a un formato triangulado: marca, influencer y usuario digital (advocate). ${ }^{2}$

\subsection{Indicadores de Muestreo}

El proceso de categorización requiere una muestra sustancial de mensajes (posts) seleccionados de las cuentas de Instagram de Gucci (@gucci),Loewe (@loewe) y Margiela (@maisonmargiela).La selección de las marcas en línea con el estudio de la influencia en redes se justifica atendiendo a una serie de criterios vinculados a informes financieros (Global Powers of Luxury Goods 2019) publicados por entidades científicas y profesionales dedicadas al mundo de la consultoría y auditoría empresarial (Grupo Deloitte) en el los que se describe que:

- Se trata de marcas de moda y lujo con presencia internacional que pertenecen a holdings de referencia en el ámbito de la moda: Gucci (Kering), Loewe (LVMH) y Margiela (OTB).

- Las tres firmas trabajan con influencers que abarcan diferentes tamaños de comunidades de seguidores, aunque como criterio generalizado se eligen posts que alcancen un mínimo de $10 \mathrm{~K}$, con objeto de analizar perfiles de micro y macroinfluencers (Pérez Curiel y Luque Ortiz, 2017).

- En los tres casos se han multiplicado las acciones en las redes sociales como vehículo de difusión y viralización de los mensajes.

- El perfil del influencer ocupa un espacio protagonista en las redes de la marca, especialmente en Instagram.

- En sus estrategias de comunicación y marketing contemplan el recurso de figuras como macroinfluencers y microinfluencers, según tipología de campaña y de producto.

\footnotetext{
2 Usuario de las redes sociales, con mayor o menor relevancia, que es cliente-consumidor de esa marca. La promoción de la marca no parte de una retribución económica sino de una verdadera pasión en la defensa de las cualidades de los productos / servicios.
} 
De este modo, si bien no se trata de un estudio que implique la totalidad del universo de todas las marcas de moda y lujo operativas en el mercado, ofrece una perspectiva global del sector, primando el interés y análisis de los posts generales (3756) y específicos (240) publicados por las marcas.

En cuanto al contexto digital, se selecciona la plataforma Instagram, reconocida como la red más seguida por los usuarios (IAB, 2019) y más influyente (Larsson, 2017) entre el sector de jóvenes adolescentes y adultos jóvenes, especialmente en lo que concierne al consumo de productos y servicios vinculados a la moda y la cosmética. Asimismo, para garantizar el rigor del estudio y la comparabilidad entre las mencionadas cuentas, la observación se llevó a cabo durante los tres últimos meses (octubre-diciembre de 2019), estableciendo una temporalización no coincidente con la celebración de las Fashion Weeks internacionales, fechas en las que la difusión de mensajes y de campañas publicitarias se multiplican en la red, con la posible distorsión del contexto real y rutinario de las marcas. La recuperación de los posts totales $(\mathrm{n} 1=3.756)$ se realiza a través de una herramienta especializada creada por Digitonomy, que accede a los datos a través de la Interfaz de Programación de Aplicaciones de Instagram (API). Para elegir los posts específicos (n2=240) se seleccionan un total de 12 hashtags (cuatro por cada marca), vinculados a la temática moda/cosmética, de los que se extraen los primeros 20 posts de influencers con más de 10K (código de microinfluencers):

- Gucci: (\#gucciophidia); (\#guccicruise20); (\#gucciflora); (\#gucciss20)

- Loewe: (\#loewess19); (\#loewefw19); (\#loewe); (\#loewedemorgan)

- Margiela: (\#maisonmargiela); (\#maisonmargielafragances); (\#glamslam); (\#whispersinthelibrary).

Para garantizar la recuperación de todo el contenido publicado durante el período muestral, los datos se trataron mediante una ficha de análisis cuantitativa y cualitativa dirigida a medir y comparar acciones y niveles de influencia en cada una de las cuentas de Instagram, que incluye las siguientes variables: (1) Número de seguidores, (2) Recuento de me gusta, (3) Recuento de comentarios, (4) Temática general, (5) Temática específica, (6) Objetivo del post, (7) Recursos multimedia del post, (8) Objetivo del comentario, (9) Tono del comentario y (10) Respuestas de la marca a los usuarios.

Tabla 1. Métodos y Tipología de Variables

\begin{tabular}{|c|c|c|}
\hline Marcas y Plataforma & Métodos & Codificadores Nariables \\
\hline \multirow{7}{*}{$\begin{array}{l}\text { Gucci (@gucci), } \\
\text { Loewe (@loewe) } \\
\text { Margiela (@maisonmargiela) }\end{array}$} & \multirow{4}{*}{ Análisis Cuantitativo } & $\mathrm{N}^{\circ}$ de Posts \\
\hline & & Perfil del influencer: Macro/Micro \\
\hline & & Métricas: Me gusta/ Comentarios /Respuestas \\
\hline & & Frecuencia \\
\hline & \multirow{3}{*}{ Análisis Cualitativo } & Temática \\
\hline & & $\begin{array}{l}\text { Recursos propios (hashtags, menciones, eti- } \\
\text { quetas, vídeos, imágenes, otros) }\end{array}$ \\
\hline & & Nivel de respuesta e interacción \\
\hline
\end{tabular}

Fuente: Elaboración propia

El programa elegido para el procesamiento de datos es el IBM SPSS Statistics, Versión 24. La fiabilidad de los intercodificadores se ha calculado con la fórmula Pi de Scott, alcanzando un nivel de error de 0,98 .

En segundo lugar, los resultados de esta primera fase fueron confirmados por un grupo de profesionales y académicos vinculados al ámbito de la moda, para validar y refinar la muestra desde una perspectiva más amplia y objetiva. Aplicamos el denominado panel de expertos, una técnica 
de amplia tradición en la investigación de tipo cualitativo en ciencias sociales (Gideon, 2012), que consiste en la discusión y búsqueda del consenso a partir de las opiniones del grupo, recogidas a través de un cuestionario y dirigidas a obtener un conocimiento más profundo del tema.

Los participantes seleccionados para el estudio proceden del ámbito de la industria de la moda, así como del ámbito científico. El principal criterio de selección responde, en el caso de los académicos, a una dilatada experiencia en investigación en el ámbito de la comunicación, la publicidad y el marketing mientras que en el área profesional cuentan con una reconocida relación contractual o de colaboración con las marcas seleccionadas.

En este sentido, Paula Cánovas participa como experta en estampación en Gucci. Ha colaborado con la marca en el ámbito de la producción y la consultoría estratégica. En el caso de Loewe, Pablo Mora participa como brand content specialist y en el de Margiela se ha contado con la participación de Ernesto Naranjo, diseñador del equipo creativo de la marca. En el ámbito académico, se suma la colaboración de Marco Pedroni, especialista en estudios sociológicos y consumo de moda y profesor de la Universidad E-Campus de Novedrate (Italia), de Marian Tavares de la Universidade do Algarve (Portugal), experta en estudios culturales y tendencias y de la profesora Irene García Medina procedente de Glasgow Caledonian University (Reino Unido) con una extensa experiencia como investigadora en el estudio social de la moda.

En esta clasificación se descarta la participación de influencers, dado que no forman parte del código "panel de expertos" y, además, constituyen uno de los objetos de estudio de investigación desde un enfoque centrado en las propias marcas y los prosumidores e instagramers.

En orden a contar con su opinión acerca de la dinámica que siguen estas marcas de moda y lujo con respecto a influencers y consumidores y a conocer si se vislumbra una nueva tendencia que potencie otras fórmulas de promoción del producto y la imagen de marca, se elaboró un informe con la explotación de los resultados obtenidos para poder discutir durante la celebración del panel.

Tabla 2. Bloques temáticos del Panel de Expertos

\begin{tabular}{|c|c|c|}
\hline Marca & Influencer & Consumidor \\
\hline EDM- Estrategia de marca & ACl-Acciones con influencers & NDE-Nivel de engagement \\
\hline
\end{tabular}

Fuente: Elaboración propia

Las entrevistas tuvieron lugar el 16 de enero de 2020 en la Universidad de Sevilla, con una duración aproximada de 107 minutos, utilizando formato presencial y online. El desarrollo fue fluido y colaborativo.

\section{Análisis de Resultados}

\subsection{Bloque de Cuantificación Estadística}

Engloba las variables numéricas, relacionadas con las métricas (número de seguidores, posts, hashtags, likes, comentarios y respuestas) computados en las cuentas de Instagram de Gucci, Loewe y Margiela.

Durante la fase de muestreo, Gucci obtiene una cota $(39,9 \mathrm{M})$ que supera en demasía a Margiela (3M) y Loewe (2 M). Siguiendo el criterio de selección de posts (240), publicados por un perfil de usuarios que alcanza como mínimo los 10.000 seguidores en Instagram (10K) y que pueden superar los $50.000(50 \mathrm{~K})$ se constata la presencia de macro y microinfluencers en las cuentas de las marcas. 
Gráfica 1. Perfil de Influencers y $\mathrm{N}^{\mathrm{o}}$ de seguidores (\%)

\section{\% influencers Macro/Micro}

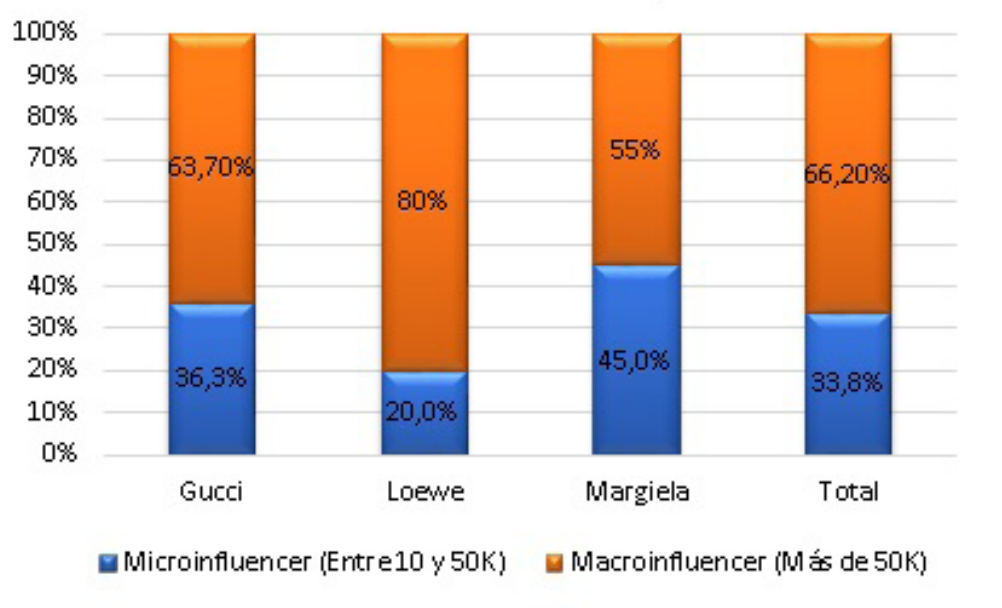

Fuente: elaboración propia

La gráfica 1 muestra que, en todos los casos, el porcentaje de macroinfluencers (56,20\%) supera a los microinfluencers $(33,8 \%)$. El máximo índice lo alcanza la firma Loewe (80\%), seguida por Margiela (55\%) y por Gucci $(53,70 \%)$. Estos datos revelan también que el factor de influencia no viene determinado sólo por el número de seguidores, sino que reside en el modelo de estrategias de comunicación y marketing para acceder a los públicos, generar difusión, convertir en trending topic el mensaje y convencerles para su compra, como eslabón final de la cadena productiva (Khan, 2018).

Tabla 3. Contingencia entre Marca y Objetivo del Post

\begin{tabular}{|c|c|c|c|c|c|c|c|c|c|}
\hline \multicolumn{10}{|c|}{ Objetivo del post } \\
\hline & & & $\begin{array}{l}\text { Promo- } \\
\text { ción } \\
\text { marca }\end{array}$ & $\begin{array}{l}\text { Promo- } \\
\text { ción pro- } \\
\text { ducto }\end{array}$ & $\begin{array}{l}\text { Promo- } \\
\text { ción dir. } \\
\text { creativo }\end{array}$ & $\begin{array}{l}\text { Promo- } \\
\text { ción in- } \\
\text { fluencer }\end{array}$ & $\begin{array}{l}\text { Promo- } \\
\text { ción cele- } \\
\text { brities }\end{array}$ & Otros & TOTAL \\
\hline \multirow{9}{*}{$\begin{array}{l}\text { Nom- } \\
\text { bre de } \\
\text { la mar- } \\
\text { ca }\end{array}$} & \multirow{3}{*}{ Gucci } & Recuento & 47 & 16 & 3 & 10 & 4 & 0 & 80 \\
\hline & & $\begin{array}{l}\text { \% dentro } \\
\text { de Nombre } \\
\text { de la marca }\end{array}$ & $58,8 \%$ & $20,0 \%$ & $3,8 \%$ & $12,5 \%$ & $5,0 \%$ & $0,0 \%$ & $100,0 \%$ \\
\hline & & $\%$ del total & $19,6 \%$ & $6,7 \%$ & $1,3 \%$ & $4,2 \%$ & $1,7 \%$ & $0,0 \%$ & $33,3 \%$ \\
\hline & \multirow{3}{*}{ Loewe } & Recuento & 45 & 13 & 3 & 14 & 2 & 3 & 80 \\
\hline & & $\begin{array}{l}\text { \% dentro } \\
\text { de Nombre } \\
\text { de la marca }\end{array}$ & $56,3 \%$ & $16,3 \%$ & $3,8 \%$ & $17,5 \%$ & $2,5 \%$ & $3,8 \%$ & $100,0 \%$ \\
\hline & & $\%$ del total & $18,8 \%$ & $5,4 \%$ & $1,3 \%$ & $5,8 \%$ & $0,8 \%$ & $1,3 \%$ & $33,3 \%$ \\
\hline & \multirow{3}{*}{ Margiela } & Recuento & 5 & 64 & 0 & 7 & 0 & 4 & 80 \\
\hline & & $\begin{array}{l}\text { \% dentro } \\
\text { de Nombre } \\
\text { de la marca }\end{array}$ & $6,3 \%$ & $80,0 \%$ & $0,0 \%$ & $8,8 \%$ & $0,0 \%$ & $5,0 \%$ & $100,0 \%$ \\
\hline & & $\%$ del total & $2,1 \%$ & $26,7 \%$ & $0,0 \%$ & $2,9 \%$ & $0,0 \%$ & $1,7 \%$ & $33,3 \%$ \\
\hline \multirow[t]{3}{*}{ Total } & Recuento & 97 & 93 & 6 & 31 & 6 & 7 & 240 & \\
\hline & $\begin{array}{l}\text { \% dentro de } \\
\text { Nombre de } \\
\text { la marca }\end{array}$ & $40,4 \%$ & $38,8 \%$ & $2,5 \%$ & $12,9 \%$ & $2,5 \%$ & $2,9 \%$ & $100,0 \%$ & \\
\hline & $\%$ del total & $40,4 \%$ & $38,8 \%$ & $2,5 \%$ & $12,9 \%$ & $2,5 \%$ & $2,9 \%$ & $100,0 \%$ & \\
\hline
\end{tabular}

Fuente: elaboración propia 
Como muestran los porcentajes de resultados (Tabla 3), los posts publicados se concentran en la promoción de la marca y del producto por delante del influencer. Destacan los mensajes dirigidos a reforzar la imagen de marca en Gucci (58.8\%) y en Loewe (56,3\%), mientras que en Margiela es el producto, el ítem, que concentra la máxima atención del post $(80 \%)$.

Imagen 1. Objetivo del post: potenciar la identidad de marca en Loewe

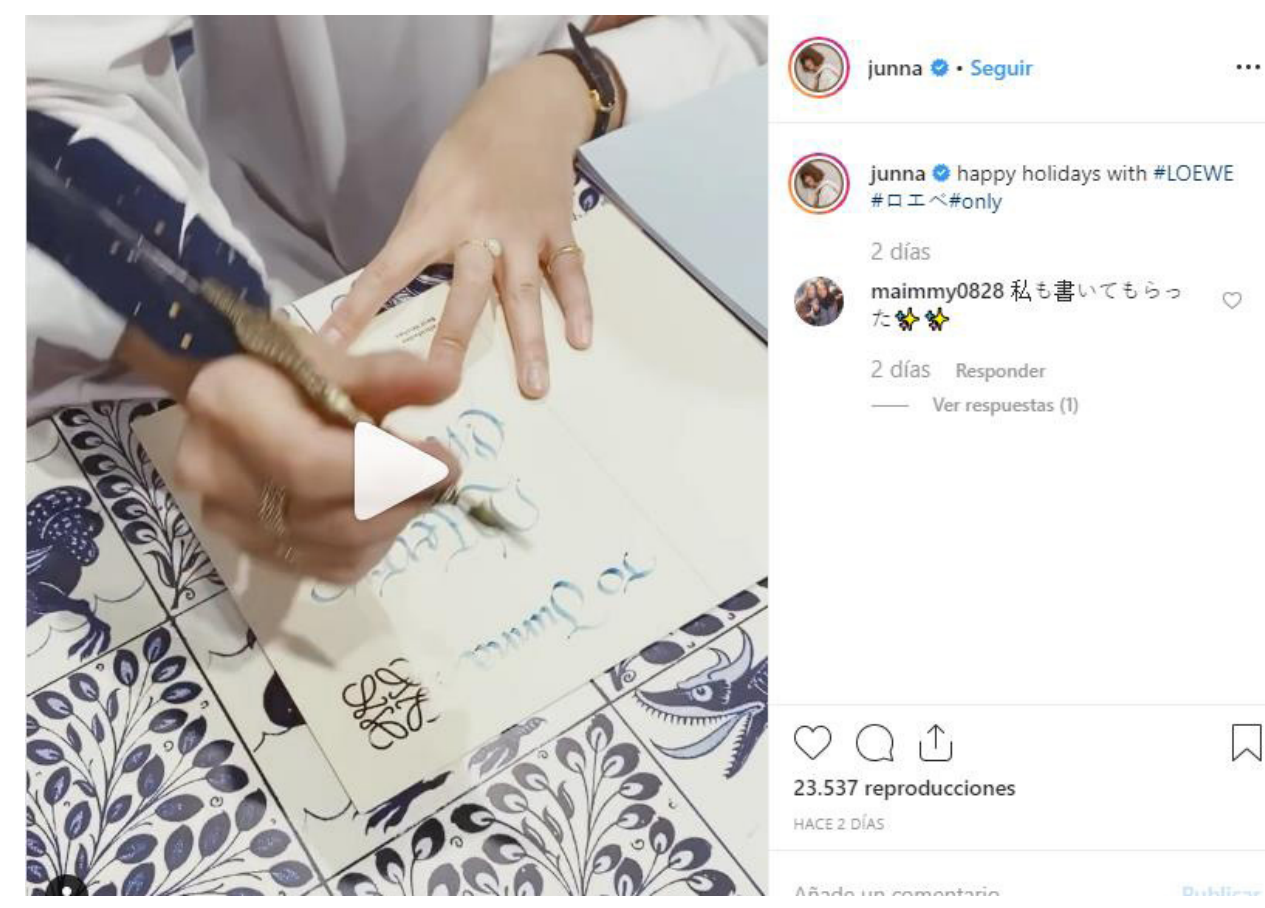

Fuente: Instagram

Imagen 2. Objetivo del post: potenciar el producto en Margiela
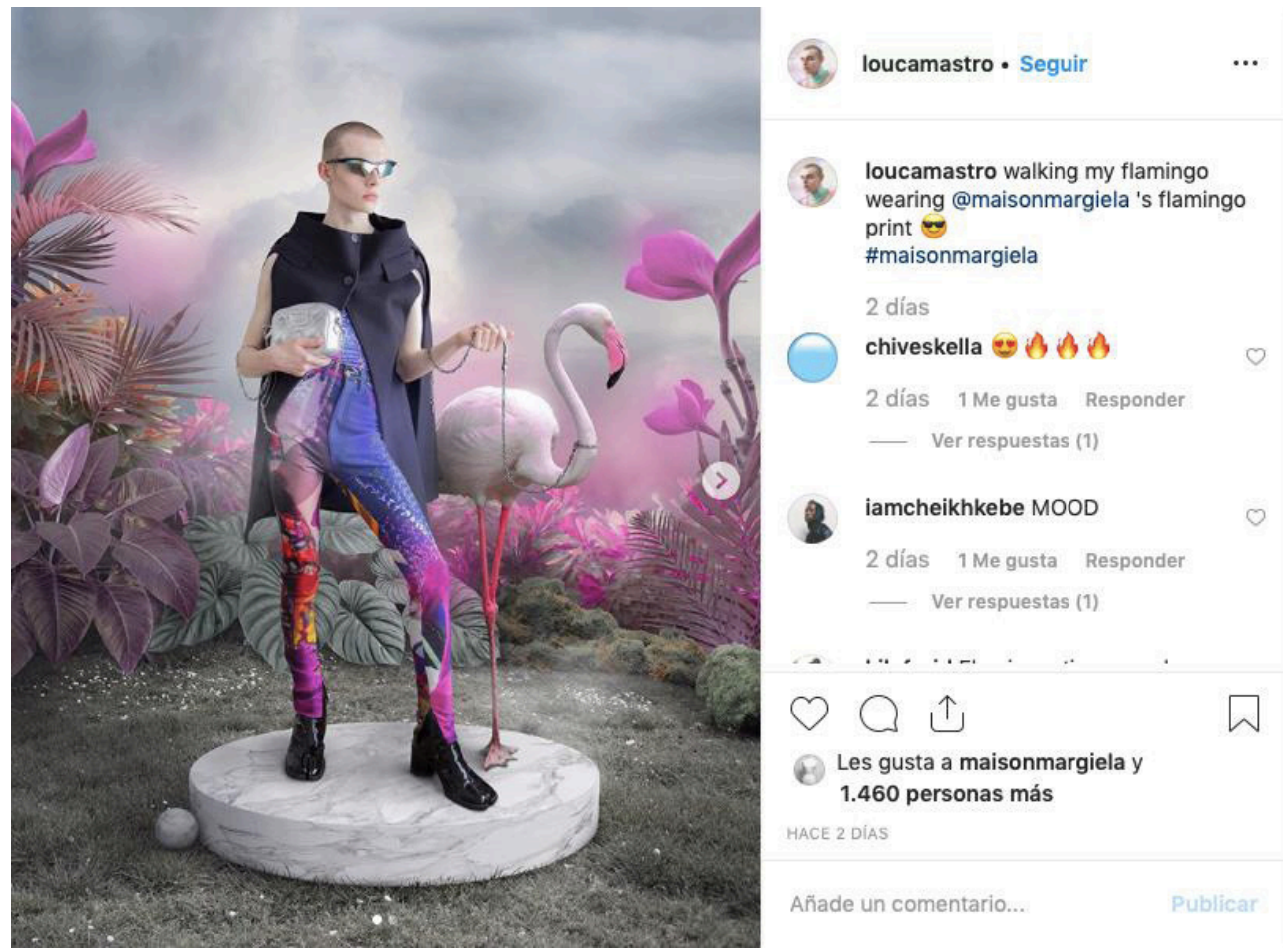

Fuente: Instagram 
Imagen 3. Objetivo del post: potenciar la identidad de marca en Gucci

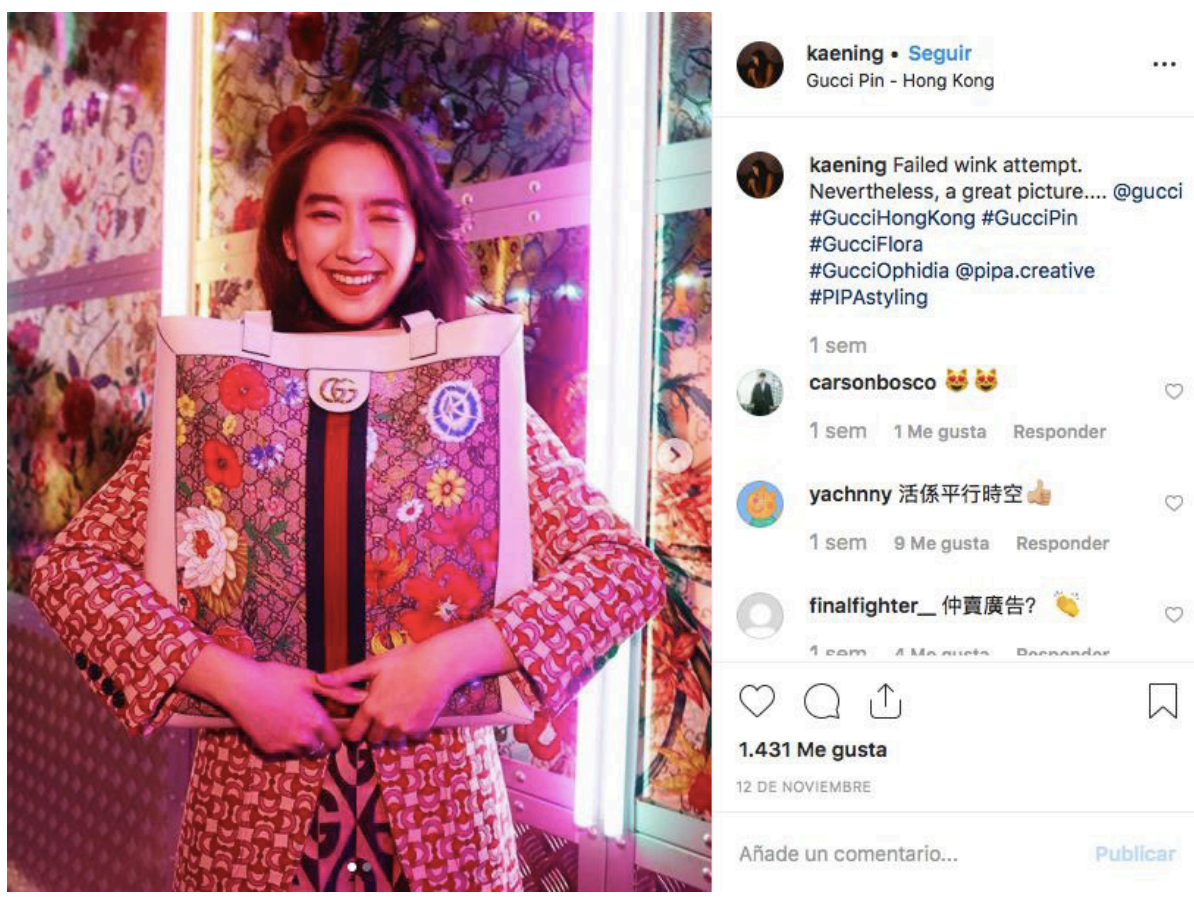

Fuente: Instagram

Como contraste, los valores de promoción de la figura del influencer, aunque ocupan un tercer lugar por delante de otros registros (director creativo y celebrities), son inferiores y reflejan un menor protagonismo. De las tres marcas analizadas, Loewe es la que mayor número de posts con referencia a influencers muestra (17,5\%) frente a los porcentajes de Gucci (12,5\%) y de Margiela $(8,8 \%)$.

Imagen 4. Objetivo del post: promoción del influencer en Loewe

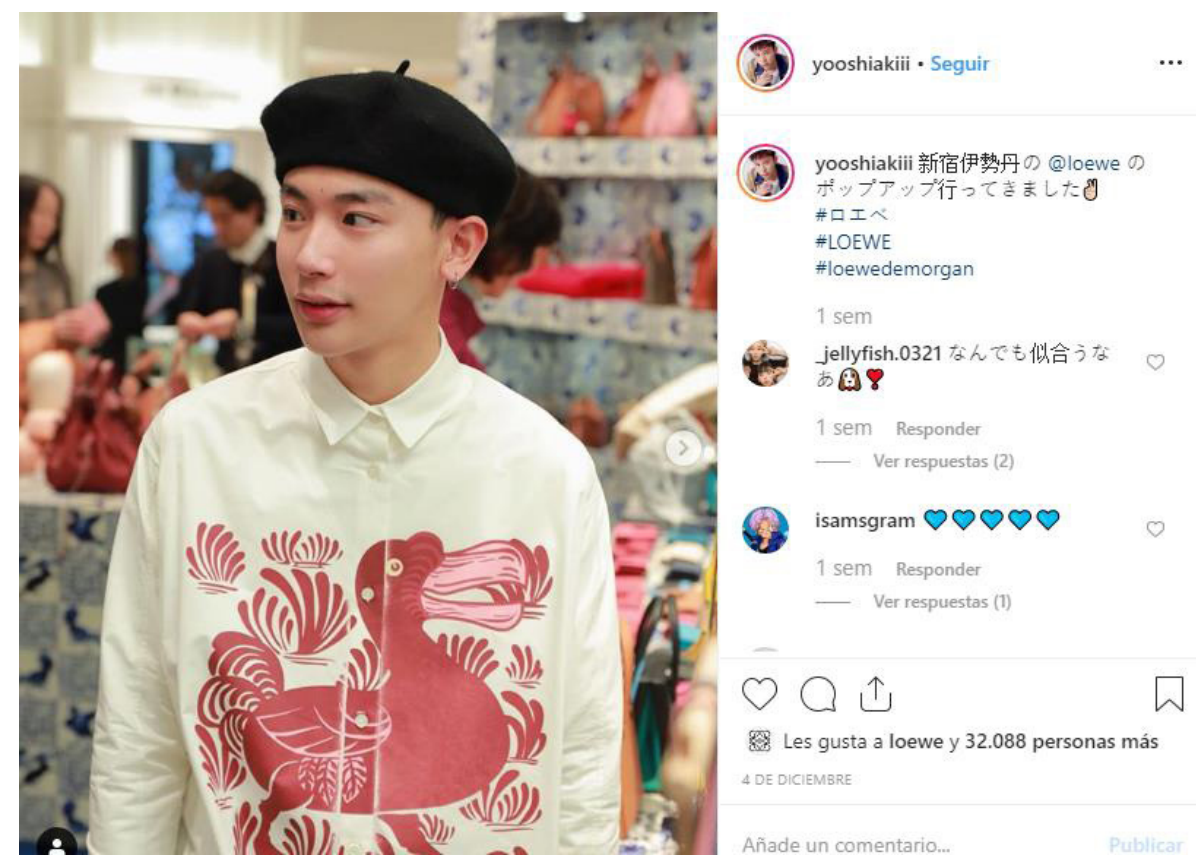

Fuente: Instagram

Los datos confirman una tendencia a potenciar la identidad de marca y la publicidad del producto, como estrategia alternativa y también complementaria al uso de influencers. 
Tabla 4. Niveles de frecuencia de fuentes mencionadas en el post

\begin{tabular}{|l|l|r|r|r|c|}
\hline \multicolumn{1}{|c|}{ Objetivo del post } & Frecuencia & Porcentaje & $\begin{array}{c}\text { Porcentaje } \\
\text { válido }\end{array}$ & $\begin{array}{c}\text { Porcentaje } \\
\text { acumulado }\end{array}$ \\
\hline \multirow{4}{*}{ Válido } & Promoción de la marca & 97 & 40,4 & 40,4 & 40,4 \\
\cline { 2 - 6 } & Promoción el producto & 93 & 38,8 & 38,8 & 79,2 \\
\cline { 2 - 6 } & Promoción del director creativo & 6 & 2,5 & 2,5 & 81,7 \\
\cline { 2 - 6 } & Promoción del influencer & 31 & 12,9 & 12,9 & 94,6 \\
\cline { 2 - 6 } & Promoción de celebrities & 6 & 2,5 & 2,5 & 97,1 \\
\cline { 2 - 6 } & Otros & 7 & 2,9 & 2,9 & 100,0 \\
\cline { 2 - 6 } & Total & 240 & 100,0 & 100,0 & \\
\hline
\end{tabular}

Fuente: elaboración propia

Cuantitativamente, los porcentajes globales de frecuencia (Tabla 4) relativos a las tres empresas de moda, confirman también la teoría de la revalorización de marca $(40,4 \%)$ y producto $(38,8 \%)$ frente a un porcentaje de presencia inferior del influencer (12,9\%). La promoción del directos creativo de la marca y de las celebrities $(2,5 \%)$ no alcanzan porcentajes referentes y muestran cómo el foco dominante se sitúa en la promoción de marca y producto.

Importa entonces definir los mecanismos aplicados por cada una de las marcas (relevancia de los temas, uso de fuentes, calidad de los recursos de la red, modos de difusión del producto) como parte de una dinámica en la que el protagonismo de los clientes y la respuesta al consumidor se convierten en objetivo clave de las estrategias de branding.

\subsection{Bloque de Cualificación Estadística}

El bloque de cualificación incorpora todos los resultados relativos a estrategias de las marcas y respuesta de los consumidores.

Las tres firmas comparten un denominador temático común: moda y cosmética. Se trata de dos líneas que definen el producto estrella de la marca y que se corresponde con la mayor demanda de información de los usuarios.

Tabla 5. Contingencia Marca/Tema General del Post

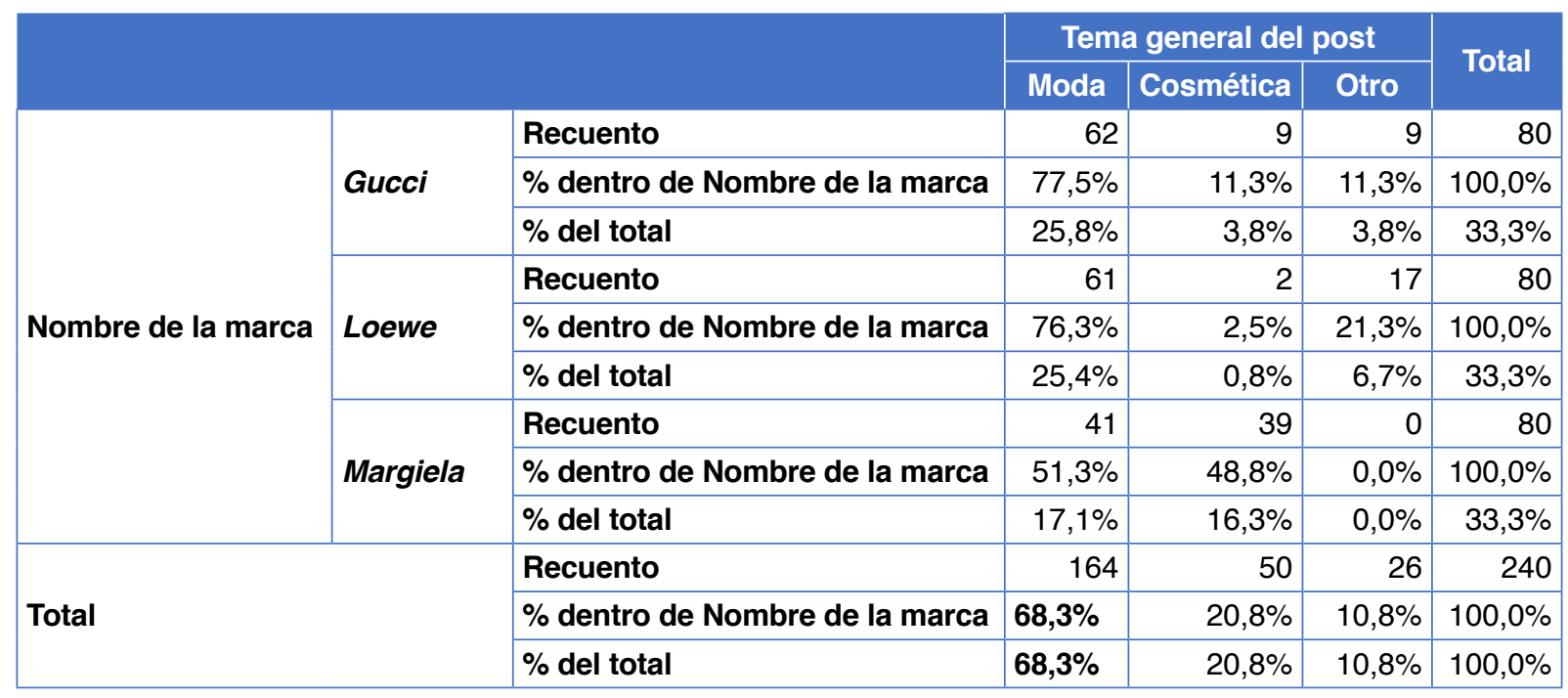

Fuente: elaboración propia 
Como indica la lectura (Tabla 5), los temas que tratan moda $(68,3 \%)$ se posicionan por delante de cosmética $(20,8 \%)$ y otros $(10,8 \%)$. Tal y como recogen los últimos informes económicos publicados por Gucci (Kering 2019), Loewe (LVMH 2018) y Margiela (OTB 2019), el perfil del cliente de las firmas de lujo otorga prioridad a la compra de productos de moda, aunque el usuario online, $m i$ llennial (Padilla Castillo y Oliver González, 2018; Martínez Salas, Segarra-Saavedra y Montserrat Gauchí, 2018) o de la Generación X y Baby Boomers (Aguilera y Baños 2016), muestra bastante interés en el consumo de productos más asequibles a esa franja de edad.

Gucci se sitúa como marca con mayor número de posts referidos a moda $(77,5 \%)$ frente a Loewe $(76,3 \%)$ y Margiela, con un porcentaje inferior (51,3\%). Sin embargo, es esta marca la que alcanza en el área de cosmética un porcentaje muy superior $(48,8 \%)$ frente al conseguido por Gucci $(11,3 \%)$ o Loewe (2,5\%). Los productos de cosmética se han convertido en alternativa principal de ventas para algunas empresas, dado que son más asequibles para un público más amplio y diverso, propio de las redes sociales. En cualquier caso, la moda sigue ocupando el primer puesto con respecto al resto de temáticas.

Tabla 6. Contingencia Marca /Tema Específico del Post

\begin{tabular}{|c|c|c|c|c|c|c|c|c|c|c|}
\hline & \multicolumn{7}{|c|}{ Tema especiffico del post } & \multirow[b]{2}{*}{ Total } \\
\hline & & & $\begin{array}{l}\text { Producto } \\
\text { de moda }\end{array}$ & $\begin{array}{l}\text { Producto } \\
\text { de cosmé- } \\
\text { tica }\end{array}$ & $\begin{array}{c}\text { Acceso- } \\
\text { rios }\end{array}$ & Evento & $\begin{array}{l}\text { Sorteo } \\
\text { o con- } \\
\text { cursos }\end{array}$ & $\begin{array}{c}\text { Campa- } \\
\text { ña publi- } \\
\text { citaria }\end{array}$ & Otros & \\
\hline \multirow{9}{*}{$\begin{array}{l}\text { Nombre } \\
\text { de la } \\
\text { marca }\end{array}$} & \multirow{3}{*}{ Gucci } & Recuento & 3 & 9 & 20 & 43 & 0 & 3 & 2 & 80 \\
\hline & & $\begin{array}{l}\% \text { dentro } \\
\text { de Nom- } \\
\text { bre de la } \\
\text { marca }\end{array}$ & $3,8 \%$ & $11,3 \%$ & $25,0 \%$ & $53,8 \%$ & $0,0 \%$ & $3,8 \%$ & $2,5 \%$ & $100,0 \%$ \\
\hline & & $\begin{array}{l}\% \text { del } \\
\text { total }\end{array}$ & $1,3 \%$ & $3,8 \%$ & $8,3 \%$ & $17,9 \%$ & $0,0 \%$ & $1,3 \%$ & $0,8 \%$ & $33,3 \%$ \\
\hline & \multirow{3}{*}{ Loewe } & Recuento & 22 & 1 & 16 & 15 & 0 & 14 & 12 & 80 \\
\hline & & $\begin{array}{l}\% \text { dentro } \\
\text { de Nom- } \\
\text { bre de la } \\
\text { marca }\end{array}$ & $27,5 \%$ & $1,3 \%$ & $20,0 \%$ & $18,8 \%$ & $0,0 \%$ & $17,5 \%$ & $15,0 \%$ & $100,0 \%$ \\
\hline & & $\begin{array}{l}\% \text { del } \\
\text { total }\end{array}$ & $9,2 \%$ & $0,4 \%$ & $6,7 \%$ & $6,3 \%$ & $0,0 \%$ & $5,8 \%$ & $5,0 \%$ & $33,3 \%$ \\
\hline & \multirow{3}{*}{ Margiela } & Recuento & 12 & 31 & 26 & 0 & 1 & 8 & 2 & 80 \\
\hline & & $\begin{array}{l}\% \text { dentro } \\
\text { de Nom- } \\
\text { bre de la } \\
\text { marca }\end{array}$ & $15,0 \%$ & $38,8 \%$ & $32,5 \%$ & $0,0 \%$ & $1,3 \%$ & $10,0 \%$ & $2,5 \%$ & $100,0 \%$ \\
\hline & & $\begin{array}{l}\% \text { del } \\
\text { total }\end{array}$ & $5,0 \%$ & $12,9 \%$ & $10,8 \%$ & $0,0 \%$ & $0,4 \%$ & $3,3 \%$ & $0,8 \%$ & $33,3 \%$ \\
\hline \multirow{3}{*}{ Total } & & Recuento & 37 & 41 & 62 & 58 & 1 & 25 & 16 & 240 \\
\hline & & $\begin{array}{l}\% \text { dentro } \\
\text { de Nom- } \\
\text { bre de la } \\
\text { marca }\end{array}$ & $15,4 \%$ & $17,1 \%$ & $25,8 \%$ & $24,2 \%$ & $0,4 \%$ & $10,4 \%$ & $6,7 \%$ & $100,0 \%$ \\
\hline & & $\begin{array}{l}\% \text { del } \\
\text { total }\end{array}$ & $15,4 \%$ & $17,1 \%$ & $25,8 \%$ & $24,2 \%$ & $0,4 \%$ & $10,4 \%$ & $6,7 \%$ & $100,0 \%$ \\
\hline
\end{tabular}

Fuente: elaboración propia 
Tal y como reflejan los datos de temática específica (Tabla 6), los accesorios $(25,8 \%)$, los eventos de moda $(24,2 \%)$, los productos de cosmética $(17,1 \%)$ y los productos de moda $(15,46 \%)$ lideran por este orden el interés del público, por delante de campañas publicitarias $(10,4 \%)$. Desde esta perspectiva se refuerza la teoría de que los millennials en Instagram (IAB, 2019) son los principales consumidores online, demandando un tipo de producto acorde a sus posibilidades económicas pero que represente los códigos de lujo y de referencia de la marca. En el caso de Gucci destacan los posts relacionados con eventos $(53,8 \%)$ frente a Loewe, marca que destaca especialmente el producto de moda $(27,5 \%)$ y Margiela que, alcanza porcentajes máximos en cosmética $(38,8 \%)$ y accesorios $(32,5 \%)$, en línea con el consumo y las posibilidades económicas de las nuevas generaciones.

El reto de escuchar a las audiencias digitales y responder a sus comentarios puede constituir el secreto del éxito de aquellas marcas que se reposicionan, cambian su imagen corporativa y diseñan un producto de lujo apto para una nueva generación de clientes.

Tabla 7. Contingencia de datos globales relativos a marca y comentarios

\begin{tabular}{|c|c|c|c|c|c|c|c|c|c|c|}
\hline & \multicolumn{7}{|c|}{ Objetivo del comentario } & \multirow[b]{2}{*}{ Total } \\
\hline & & & $\begin{array}{l}\text { No } \\
\text { hay }\end{array}$ & $\begin{array}{l}\text { Pro- } \\
\text { ducto }\end{array}$ & $\begin{array}{l}\text { Men- } \\
\text { ciona la } \\
\text { marca }\end{array}$ & $\begin{array}{c}\text { Menciona } \\
\text { al influen- } \\
\text { cer }\end{array}$ & $\begin{array}{c}\text { Dudas, que- } \\
\text { jas o suge- } \\
\text { rencias }\end{array}$ & $\begin{array}{l}\text { Emoti- } \\
\text { conos }\end{array}$ & Otros & \\
\hline \multirow{9}{*}{$\begin{array}{l}\text { Nombre } \\
\text { de la } \\
\text { marca }\end{array}$} & \multirow{3}{*}{ Gucci } & Recuento & 0 & 18 & 1 & 39 & 2 & 14 & 6 & 80 \\
\hline & & $\begin{array}{l}\% \text { dentro } \\
\text { de Nombre } \\
\text { de la mar- } \\
\text { ca }\end{array}$ & $0,0 \%$ & $22,5 \%$ & $1,3 \%$ & $48,8 \%$ & $2,5 \%$ & $17,5 \%$ & $7,5 \%$ & $100,0 \%$ \\
\hline & & $\%$ del total & $0,0 \%$ & $7,5 \%$ & $0,4 \%$ & $16,3 \%$ & $0,8 \%$ & $5,8 \%$ & $2,5 \%$ & $33,3 \%$ \\
\hline & \multirow{3}{*}{ Loewe } & Recuento & 0 & 14 & 10 & 33 & 4 & 16 & 3 & 80 \\
\hline & & $\begin{array}{l}\% \text { dentro } \\
\text { de Nombre } \\
\text { de la mar- } \\
\text { ca }\end{array}$ & $0,0 \%$ & $17,5 \%$ & $12,5 \%$ & $41,3 \%$ & $5,0 \%$ & $20,0 \%$ & $3,8 \%$ & $100,0 \%$ \\
\hline & & $\%$ del total & $0,0 \%$ & $5,8 \%$ & $4,2 \%$ & $13,8 \%$ & $1,7 \%$ & $6,7 \%$ & $1,3 \%$ & $33,3 \%$ \\
\hline & \multirow{3}{*}{ Margiela } & Recuento & 11 & 39 & 0 & 19 & 3 & 7 & 1 & 80 \\
\hline & & $\begin{array}{l}\% \text { dentro } \\
\text { de Nombre } \\
\text { de la mar- } \\
\text { ca }\end{array}$ & $13,8 \%$ & $48,8 \%$ & $0,0 \%$ & $23,8 \%$ & $3,8 \%$ & $8,8 \%$ & $1,3 \%$ & $100,0 \%$ \\
\hline & & $\%$ del total & $4,6 \%$ & $16,3 \%$ & $0,0 \%$ & $7,9 \%$ & $1,3 \%$ & $2,9 \%$ & $0,4 \%$ & $33,3 \%$ \\
\hline \multirow{3}{*}{ Total } & & Recuento & 11 & 71 & 11 & 91 & 9 & 37 & 10 & 240 \\
\hline & & $\begin{array}{l}\% \text { dentro } \\
\text { de Nombre } \\
\text { de la mar- } \\
\text { ca }\end{array}$ & $4,6 \%$ & $29,6 \%$ & $4,6 \%$ & $37,9 \%$ & $3,8 \%$ & $15,4 \%$ & $4,2 \%$ & $100,0 \%$ \\
\hline & & $\%$ del total & $4,6 \%$ & $29,6 \%$ & $4,6 \%$ & $37,9 \%$ & $3,8 \%$ & $15,4 \%$ & $4,2 \%$ & $100,0 \%$ \\
\hline
\end{tabular}

Fuente: elaboración propia

Destacamos los resultados (Tabla 7) que revelan cómo la mayoría de los comentarios de los usuarios mencionan en primer lugar al influencer $(37,9 \%)$ seguido del producto $(29,6 \%)$ y del uso de emoticonos $(15,4 \%)$, quedando la marca relegada a un cuarto lugar $(4,6 \%)$. Los seguidores de las cuentas de las tres marcas en Instagram continúan manifestando un interés primario hacia esta figura y comentan sobre su vida personal, su imagen o sobre las stories que los líderes suben a la red. Sin embargo, los datos confirman que el producto sigue siendo un factor relevante en los comentarios, aunque habría que comprobar si se trata del producto que difunde la marca o de otro producto vinculado al influencer. 
Gucci alcanza el mayor número de comentarios de instagramers dirigidos al influencer $(48,8 \%)$, por delante de Loewe (41,3\%) y Margiela $(23,8 \%)$, mientras que el foco máximo de comentarios para esta firma lo alcanza el producto $(48,8 \%)$, frente a Gucci $(22,5 \%)$ y Loewe $(17,5 \%)$, respectivamente.

El empoderamiento del público digital no ha sido calibrado por aquellas marcas que siguen viendo en las redes un marco de comunicación unidireccional, un escenario que ni la acción del influencer (Jiyoung y Ko, 2010) puede solucionar. Comprobar el nivel de respuesta y engagement de las tres firmas de lujo con los instagramers es clave cuando parece que la tendencia del nuevo marketing concentra la atención en los prosumidores (Correia Loureiro, Serra y Guerreiro, 2018).

Tabla 8. Contingencia Marca/Respuesta/Tono del Comentario

\begin{tabular}{|c|c|c|c|c|c|c|c|}
\hline & & & \multicolumn{3}{|c|}{ Responde a los comentarios } & \multicolumn{2}{|c|}{ Tono del comentario } \\
\hline & & & Sin comentarios & Sí & No & Positivo & Negativo \\
\hline \multirow{9}{*}{$\begin{array}{l}\text { Nombre de } \\
\text { la marca }\end{array}$} & \multirow{3}{*}{ Gucci } & Recuento & 0 & 37 & 43 & 71 & 2 \\
\hline & & $\begin{array}{l}\% \text { dentro de Nombre } \\
\text { de la marca }\end{array}$ & $0,0 \%$ & $46,3 \%$ & $53,8 \%$ & $88,8 \%$ & $2,5 \%$ \\
\hline & & $\%$ del total & $0,0 \%$ & $15,4 \%$ & $17,9 \%$ & $29,6 \%$ & $0,8 \%$ \\
\hline & \multirow{3}{*}{ Loewe } & Recuento & 0 & 3 & 77 & 79 & 1 \\
\hline & & $\begin{array}{l}\% \text { dentro de Nombre } \\
\text { de la marca }\end{array}$ & $0,0 \%$ & $3,8 \%$ & $96,3 \%$ & $98,8 \%$ & $1,3 \%$ \\
\hline & & $\%$ del total & $0,0 \%$ & $1,3 \%$ & $32,1 \%$ & $32,9 \%$ & $0,4 \%$ \\
\hline & \multirow{3}{*}{ Margiela } & Recuento & 11 & 25 & 44 & 65 & 0 \\
\hline & & $\begin{array}{l}\text { \% dentro de Nombre } \\
\text { de la marca }\end{array}$ & $13,8 \%$ & $31,3 \%$ & $55,0 \%$ & $81,3 \%$ & $0,0 \%$ \\
\hline & & $\%$ del total & $4,6 \%$ & $10,4 \%$ & $18,3 \%$ & $27,1 \%$ & $0,0 \%$ \\
\hline \multirow{3}{*}{\multicolumn{2}{|c|}{ Total }} & Recuento & 11 & 65 & 164 & 215 & 3 \\
\hline & & $\begin{array}{l}\% \text { dentro de Nombre } \\
\text { de la marca }\end{array}$ & $4,6 \%$ & $27,1 \%$ & $68,3 \%$ & $89,6 \%$ & $1,3 \%$ \\
\hline & & $\%$ del total & $4,6 \%$ & $27,1 \%$ & $68,3 \%$ & $89,6 \%$ & $1,3 \%$ \\
\hline
\end{tabular}

Fuente: elaboración propia

El índice global de resultados (Tabla 8) muestra cómo la dinámica de no responder a los comentarios es seña de identidad de las tres marcas. La no-respuesta $(68,3 \%)$ supera el porcentaje de interacción con los instagramers $(27,1 \%)$, teniendo en cuenta que algunos posts carecen de comentarios $(4,6 \%)$, aun cuando el porcentaje de mensajes con tono positivo (a favor de la marca y el producto) supera a un índice bajo de comentarios negativos (crítica)

De manera individual destaca Loewe con un nivel de no-respuesta (96,3\%), seguida por Margiela $(55,0 \%)$ y Gucci $(53,8 \%)$. Salvo en el caso de Loewe, con un bajo nivel de respuesta, el resto de marcas muestra cierto equilibrio. Independientemente del elevado porcentaje de no-respuesta compartido por las tres marcas, destaca el tono positivo de comentario de los usuarios, denotando el interés y en algunos casos, la pasión de los instagramers, como fans (advocates) de la marca y, especialmente, de los influencers.

Investigaciones anteriores (Roca, 2015) inciden en la necesidad de la bidireccionalidad y la participación de los consumidores como baza para el éxito de las marcas en las redes.

El análisis de resultados en su primera fase dibuja un escenario en el que las marcas necesitan implementar estrategias de comunicación y marketing en red, sin desestimar el papel de los nuevos líderes de opinión (influencers) con el fin de mejorar y renovar la imagen corporativa y los beneficios 
empresariales. En esta disyuntiva inciden además otros factores como la reorientación del público objetivo, la redefinición del perfil de profesionales de la empresa y la interacción y bidireccionalidad con los usuarios, para conocer la cultura de consumo del cliente potencial.

\subsection{Bloque 3. Análisis e interpretación de resultados según el panel de expertos}

La explotación de datos durante esta tercera fase arroja conclusiones de interés para la investigación desde una doble perspectiva, académica y profesional. De manera generalizada, los profesionales de marca constatan la importancia del influencer como ítem necesario en sus estrategias de implementación y marketing. Sin embargo, estas apreciaciones contrastan con la perspectiva de los académicos, que avanzan hacia un horizonte en el que, si bien el influencer es una herramienta útil para la comunicación de las marcas de moda, no se presenta como eje esencial para el éxito comercial. No obstante, es preciso atender a la pluralidad de matices que acompañan a estos enfoques.

El panel se inicia con la presentación del informe de los resultados obtenidos durante las fases preliminares a todos los participantes. Esta cuestión manifiesta que el diseño del informe es adecuado para la obtención de resultados y la posterior discusión ya que los entrevistados no presentan indicios de confusión o problema a la hora de entender las preguntas planteadas. Al mismo tiempo, no se muestran reticentes ante ninguna de las preguntas formuladas y aceptan la dinámica con satisfacción y fluidez.

El primer dato que llama la atención a los participantes y sobre el que comienza la discusión es el número de seguidores de las cuentas analizadas. La diferencia entre las cuentas de unas marcas y otras no genera un debate reseñable en tanto que se percibe como consecuencia de la importancia, trayectoria y resultado de la imagen proyectada por estas marcas en los medios convencionales. No obstante, la académica Tavares destaca la superioridad en número de seguidores de Gucci como consecuencia de la, a su juicio, "incuestionable trayectoria" y "procesos de colaboración con $m i$ llennials" que caracteriza a la marca: "es una de las grandes marcas de moda por excelencia que ha sabido captar al público joven como difusor y cliente", perspectiva compartida por el resto de participantes.

En cuanto a las características concretas de esos influencers, la cualidad de macroinfluencer y microinfluencer reflejada en los seguidores de estas cuentas, presenta para los profesionales de moda una consecuencia directa de las estrategias planteadas por las propias marcas. Así lo describe Mora cuando afirma que la selección de estos perfiles depende en muchos casos de "los intereses de la marca" concretando que los datos evidencian que, efectivamente, Loewe no cuenta con una cantidad destacable de microinfluencers debido a que la firma "confía mucho en los macroinfluecers y celebrities [...] nosotros contamos no son sólo con influencers profesionales, sino también actores y actrices y gente del mundo de la cultura".

En el caso de Gucci, Cánovas afirma que la marca selecciona a los influencers teniendo en cuenta básicamente su impacto mediático. Estas declaraciones se relacionan estrechamente con los datos arrojados en el informe en tanto que evidencian que precisamente Margiela es la marca que cuenta con mayor representatividad de microinfluencers en sus publicaciones. En esta línea, académicos como Pedroni sostienen que "Margiela siempre ha destacado por su inclusividad". No obstante, el resto de académicos afirma que, si bien hay matices entre las marcas, es preciso recordar que estas cuestiones se relacionan muy estrechamente con la popularidad que alcanzan entre los públicos. García concreta en este sentido que "el alcance de Gucci no es el mismo que el de Margiela, es lógico que una tenga más poder a la hora de afrontar colaboraciones más potentes".

En cuanto a la importancia de la presencia del influencer en las cuentas de las marcas, los académicos coinciden en que "cuando la marca es importante, es el influencer el que se interesa por 
colaborar con ella", como concreta Tavares. Ambos sectores comparten que hay ciertos intereses de los influencers con los que las marcas juegan para beneficiarse: "Está claro que a un influencer le interesa trabajar con determinadas marcas porque eso le da credibilidad", señala Pedroni. Algo con lo que Cánovas reconoce estar completamente de acuerdo cuando expresa que "en muchos casos son ellos mismos los que contactan con nosotros para colaborar porque les interesa". No obstante, durante la conversación se comenta el caso concreto de Margiela, cuya temática evidenciada en el informe destaca por su interés en el producto por encima del influencer. A este parecer, Ernesto Naranjo afirma que "Galliano se encuentra en constante búsqueda de exclusividad, por lo que centra sus esfuerzos en el producto, no en una entidad ajena como puede ser el caso de estos perfiles".

Una vez valorados los aspectos generales del informe, preguntamos a los entrevistados por los tres elementos claves relacionados con los objetivos concretos del estudio.

Recordamos, previamente, las siglas de los elementos analizados:

Bloque temático relacionado con la marca

- EDM- Estrategia de marca

Bloque temático relacionado con el influencer

- ACI-Acciones con influencers

Bloque temático relacionado con el consumidor

- NDE-Nivel del engagement

\section{EDM- Estrategia de marca}

Los expertos de moda reconocen de manera unánime que, en efecto, la perspectiva comunicacional de las marcas ha evolucionado hacia un paradigma hasta ahora desconocido. Naranjo (Margiela) afirma que "revistas como Vogue, Elle, Harper ya no tienen tanto poder de influencia como antes, ahora los nuevos perfiles han ganado terreno". Esta apreciación es acogida por el sector de los académicos con cautela advirtiendo lo que sugirieren como un futuro incierto. Así lo estima la profesora García cuando expresa que "las marcas están perdiendo protagonismo con respecto al influencer y eso no es nada recomendable porque irá en detrimento de la imagen de la marca". Se abre el debate por parte de los profesionales que defienden la importancia de la marca por encima de cualquier activo externo. Así lo constata Mora (Loewe) cuando concreta que "nosotros controlamos muy bien el mensaje que queremos transmitir, nada se escapa a la espontaneidad, aunque las acciones del influencer parezcan naturales, ahí está el secreto".

Cuestiones como el grado de libertad del influencer a la hora de trabajar con las marcas a través de sus propias publicaciones son ampliamente debatidas entre académicos y profesionales desde diversos enfoques. Por un lado, los académicos alertan de que estos perfiles pueden no ser siempre beneficiosos para las marcas en tanto que explotan el mensaje propio por encima del objetivo de la marca: "A ellos les interesa más mostrar su personalidad que el propio producto", sostiene Tavares. Algo recogido por los profesionales que, si bien reconocen que podría ocurrir y ser un riesgo para la marca, "se trata siempre de cerrar un contrato muy claro con los objetivos e indicaciones para el influencer", aclara Mora (Loewe). Por otro lado, los profesionales defienden una postura muy proteccionista ante la marca. Cánovas pone énfasis en la identidad de marca. "En Gucci, y creo que, en todas las marcas de referencia, lo importante es la propia imagen, y eso siempre se mantiene presente en todas nuestras estrategias", reconociendo así que la figura del influencer es un factor importante cuando no clave o superior a la propia marca. Estas apreciaciones conducen de manera natural hacia el siguiente bloque relacionado con acciones directas con los influencers. 


\section{ACI-Acciones con influencers}

Los académicos señalan que las acciones con los influencers despiertan una enorme atracción en la actividad empresarial que no se corresponde con el rédito que obtiene la industria. Pedroni afirma que "las marcas se obsesionan con los influencers invirtiendo una cantidad desmesurada de dinero que no siempre redunda en los beneficios esperados". Un punto de vista compartido en gran medida por los expertos, que destacan que si bien la cantidad invertida en muchas ocasiones es excesiva "luego compensa debido al impacto mediático suscitado", según Mora (Loewe). En cualquier caso, los académicos reconocen una tendencia hacia el posicionamiento de la marca como auténtica prescriptora y líder de estrategias, por delante de la actividad del influencer.

De otro lado, el grupo de expertos manifiesta un discurso que tiende a la polarización en tanto que defienden que la inclusión de los influencers en las estrategias de moda se antoja algo "completamente necesario dada la tendencia a una narrativa digital que supera al modelo de comunicación tradicional", sostiene Naranjo (Margiela). Los colaboradores de las marcas expresan que el sector de la moda se encuentra muy ligado a las tendencias y estilos que marca la cultura del consumidor, de manera que como indica Mora: "si ahora la moda es seguir a influencers, nosotros no nos podemos quedar atrás". De hecho, Cánovas añade: "no se les puede exigir una prescripción que genere una venta, sino más bien una inspiración que motive el deseo", destacando así que el resultado esperado de las estrategias con influencers no es tanto la prescripción en la compra, como la sugestión y creación de un universo evocador que se vincule con la marca.

Estas declaraciones se refuerzan con la opinión que tienen los expertos sobre los objetivos que se persiguen a la hora de contratar a estos perfiles. Destacan ideas como el valor del influencer a la hora de conectar con el público, como indica Mora (Loewe): "llegan a comunicar el producto de manera más cercana y eficiente de lo que la marca puede hacer". Asimismo, sostienen que se trata de una "estrategia más", como afirma Naranjo (Margiela), manifestando que son parte de una estrategia global y no un fin en sí mismo. De hecho, como afirma Mora (Loewe): "no se les hacen partícipes del proceso creativo". Algo que refuerza Cánovas (Gucci) cuando declara que "Gucci no colabora con influencers durante más de dos o tres temporadas". En definitiva, las opiniones de los expertos contrastan con las de los académicos en tanto a que si bien, reconocen que las estrategias con influencers son un elemento protagonista en sus acciones, al mismo tiempo, sostienen que dichas acciones están muy controladas y supeditadas a la marca.

\section{NDE-Nivel del engagement}

En cuanto al debate focalizado en el impacto que estas estrategias suscitan en el consumidor, de nuevo, se evidencia un doble enfoque. Pedroni destaca que "las marcas deberían prestar más atención al consumidor. Parecen haberlo olvidado entre tanto influyente". Esta afirmación ha sido compartida por el resto de académicos, los cuales indican la necesidad de reforzar la imagen del producto y la marca ante el consumidor. Durante el desarrollo del panel, dedican un espacio dilatado de tiempo a argumentar la no respuesta de las marcas hacia los instagramers y potenciales consumidores digitales. En el caso de Naranjo (Margiela), reconoce que "es prácticamente imposible atender a todos los comentarios" dirigiendo la conversación hacia causas relacionadas con la popularidad de las marcas. En efecto, los profesionales justifican que debido a la importancia de sus marcas y al número de seguidores, "se hace prácticamente imposible hacer frente a todo eso", Cánovas (Gucci). En cualquier caso, Mora (Loewe) recuerda que los datos de los informes revelan que no existe tanta diferencia entre las menciones al producto y al influencer y que en la mayoría de los casos los comentarios siempre son positivos, defendiendo así el trabajo de las marcas. En relación a esto último, Cánovas declara que normalmente cuando existen comentarios negativos, críticos o polémicos "Gucci suele responder a través de sus plataformas". 
El cierre de este panel se centra en recabar, a modo de conclusión, la opinión de los participantes en torno al futuro de estos perfiles y sus estrategias con las marcas. El denominador común de todos los entrevistados responde al reconocimiento de los influencers como una herramienta que, si bien, tiende a perder posiciones en el futuro, se mantendrá por un tiempo como protagonista en el sector de la moda y el lujo.

\section{Discusión y Conclusiones}

Los resultados de la investigación han conseguido dibujar un claro escenario que describe las acciones estratégicas de las marcas de moda de lujo en el ámbito de las redes sociales. El objetivo principal encaminado a conocer el nivel de protagonismo que encarnan los influencers y su dinámica en Instagram se desglosa a partir de la metodología de triangulación comparada (Silverman, 2016; Krippendorff, 2004; Flick, 2004) aplicada a los procedimientos de comunicación y marketing de las marcas objeto de estudio. En este sentido, la investigación supone un avance para el mundo académico en lo relativo al marketing de influencia en el sector de moda y lujo en tanto que pone de relieve la necesidad de reflexionar sobre la continuidad del influencer como líder de opinión.

La hipótesis inicial que sostiene una nueva tendencia en la que se potencia la identidad de la marca con respecto al influencer, se confirma a partir de las valoraciones recogidas en el panel de expertos sobre los resultados de la medición estadística. Si bien el diálogo dibuja un mapa polarizado en temas específicos relacionados con el poder de las redes sociales, los nuevos modelos de comunicación, la relación cercana entre influencer y usuario y la unidireccionalidad y falta de interacción de las marcas, se constata cierto consenso a la hora de definir una tendencia que pasa por mantener la figura del influencer como un elemento más en las estrategias de marca implementadas en las redes sociales. En definitiva, el papel de este líder de opinión sigue ocupando un lugar visible en las campañas publicitarias (Castello-Martínez y Del-Pino-Romero (2015) que proyectan las marcas en las redes sociales (Rocamora, 2017; Pérez Curiel y Clavijo Ferreira, 2017; Sádaba y San Miguel, 2016).

No obstante, tanto desde la óptica de académicos como de profesionales, se tiende a relegar a un segundo plano la relevancia de estos perfiles. En el caso de los académicos, defienden ampliamente que se trata de una figura agotada en tanto que la inversión requerida no se corresponde con los beneficios obtenidos.

En cualquier caso y respondiendo al primer objetivo de esta investigación, el reconocimiento de la marca como prescriptor clave ante los consumidores ha alcanzado el consenso de los participantes. Se observa que los mecanismos de branding implementados evolucionan hacia un modelo de promoción centrado más intensivamente en el producto y en la marca que en el propio influencer, coincidiendo de este modo con la perspectiva de autores como Bernabel Dicent (2015), quienes destacan que la proyección de la propia identidad de estos perfiles por encima de la imagen de la marca supone una estrategia cada vez más débil en las acciones de comunicación definidas. Así lo revelan los resultados cuando avanzan que la temática de los posts se dirige en mayor medida a promocionar la marca por encima del influencer.

En cuanto al segundo objetivo, se observa que la relación entre las marcas de moda y el influencer se presenta en pleno proceso de cambio con respecto a investigaciones anteriores. Si bien hasta el momento parecían liderar las acciones de las marcas de moda a través de estrategias de la personificación de los propios mensajes de la marca (Khan, 2018), los resultados ponen de manifiesto el cambio hacia un escenario en el que prima una interacción más estrecha entre la marca y sus audiencias. De algún modo parece que las marcas priorizan el encuentro con el público por encima de las acciones con los influencers. Esta conclusión se vincula estrechamente con el tercer objetivo y 
tercera pregunta de investigación planteadas. Los resultados revelan que a pesar de que el influencer mantiene cierto protagonismo e interés para las audiencias, es cierto que el producto sigue siendo un valor determinante en los comentarios de los usuarios. Coincidiendo con Correia Loureiro, Serra y Guerreiro (2018), los datos evidencian una tendencia hacia la prevalencia de un protagonismo mayor por parte de la marca.

Asimismo, cabe señalar que, tal y como recoge la hipótesis, la tendencia de las empresas de moda y lujo es potenciar un mensaje focalizado en el producto, intensificando en paralelo la imagen de la marca y neutralizando el protagonismo del influencer. En definitiva, la marca se erige como líder para el desarrollo estratégico dado que se presupone como un activo de autenticidad y legitimidad tanto para el público como para el propio influencer. Se evidencia que la marca ocupa una posición estratégica principal en tanto que su credibilidad y resonancia son aprovechadas en beneficio del influencer, y no al contrario.

Como consecuencia, los resultados manifiestan la necesidad de reflexionar sobre las tendencias estratégicas del sector de la moda en el ámbito del social media en futuras investigaciones. De entre las recomendaciones derivadas, por un lado, un requerimiento de base es reforzar el protagonismo y la imagen de marca en todas las acciones comunicativas. Por otro, se recomienda dirigir las premisas de la comunicación y el marketing hacia la bidireccionalidad del discurso, como fórmula para incrementar la simetría con el consumidor, relegado a un segundo plano. La recomendación se dirige a implementar acciones que despierten el interés de las comunidades de fans, de los seguidores y de los potenciales clientes, que amplíen su perspectiva más allá de los vínculos aspiracionales con el influencer, devolviendo el foco y la atención a la marca como valor simbólico proyectivo y final en el proceso de difusión y consumo.

Por último y atendiendo a las limitaciones derivadas de la investigación es preciso tener en cuenta que el estudio analiza el sector de la moda desde un enfoque muy concreto como es el de las marcas de lujo, cuya idiosincrasia y naturaleza son verdaderamente complejas. En este sentido, la ampliación de la muestra, la incorporación de otras marcas identificadas con el slow fashion, no sujeto a las tendencias y a los ritmos del fast fashion, el análisis de nuevos roles dominantes en la red, así como el análisis de las nuevas narrativas digitales en otras plataformas más allá de Instagram, podrían aportar perspectivas y enfoques innovadores en el campo de la comunicación y el marketing de moda.

\section{Bibliografía}

Aguilera, J., Baños, M., \& Ramírez, F. J. (2016). Los mensajes híbridos en el marketing posmoderno: una propuesta de taxonomía. Icono 14, 14(2), 6-57. https://doi.org/10.7195/ri14. v14i1.890

Bastien, V., \& Kapferer, J. N. (2012). The Luxury Strategy: Break the rules of marketing to build luxury brands. Philadelphia: Kogan Page

Beauchamp, M. B. y Barnes, D. C. (2015). Delighting Baby Boomers and Millennials: Factors that matter most. Journal of Marketing Theory and Practice, 23(3), pp. 338-350. doi:10.1080/106 96679.2015.1032472

Bernabel Dicent, A. (2015). Identidad, deterioro y cambio de imagen de marca. Caso: calzado deportivo Kelme. Opción, 31(4), 87-105.

Bryman, A. (2016). Social research methods. Oxford: Oxford University Press.

Castelló-Martínez, A. (2016). El marketing de influencia: Un caso práctico. In I. Zacipa, V. TurViñes \& J. Segarra-Saavedra (Coords.), Tendencias publicitarias en Iberoamérica: Diálogo de 
saberes y experiencias (49-65). Alicante: Colección Mundo Digital. http://dx.doi.org/10.14198/ MEDCOM/2016/8

ClikZ Digital News, (2015). 10 most engaging luxury brands to follow on Instagram by Christopher Ratcliff. https://www.clickz. com/2015/10/28/10-most-engaging-luxury-brands-tofollow-on-instagram.

Correia Loureiro, S. M., Serra, J. \& Guerreiro, J. (2018). Fashion Brands Communicating and Interacting in Instagram: a netnography approach. Global Marketing Conference at Tokyo, Instituto Universitario de Lisboa. http://dx.doi.org/10.15444/GMC2018.11.05.04

De Veirman, M., Cauberghe, V., \& Hudders, L. (2017). Marketing through Instagram influencers: the impact of number of followers and product divergence on brand attitude. International Journal of Advertising, 36(5), 798-828. https://doi.org/10.1080/02650487.2017.1348035

Deloitte Touche Tohmatsu Limited. (2019). Informe Global Powers of Luxury Goods, 2019. https://bit.ly/2FopZzC

Díaz Soloaga, P. (2017). El valor de los intangibles en la nueva cultura digital. La opinión de profesionales y expertos de la comunicación a través del método Delphi. En J. Benavides Delgado (Coord.), Los nuevos caminos en la evolución de las marcas (33-54). Madrid: Fragua.

Díaz, L. (2017). Soy marca: quiero trabajar con influencers. Barcelona: Profit.

Ferrer González, L. J. (2018). Comportamiento del consumidor 2.0: nuevas realidades en entornos digitales. Marketing Visionario, 7(1), pp. 141-155. http://ojs.urbe.edu/index.php/market/article/ view $/ 2727$

Finch, H., \& Lewis, J. (2003). Focus groups. Qualitative research practice: A guide for social science students and researchers. In J. Ritchie \& J. Lewis (Eds.), Qualitative Research Practice: A guide for Social Science Students and Researchers (170-198). London: Sage.

Flick, U. (2004). Introducción a la metodología cualitativa. Madrid: Ediciones Morata.

Franklin, B., Hamer, M., Hanna, M., Kinsey, M., \& Richardson, J. E. (2015). Key concepts in journalism studies. London: Sage.

Gideon, L. (2012). Handbook of Survey Methodology for the Social Sciences. Berlin: Springer.

González-Romo, Z. F., \& Plaza-Romero, N. (2017). Estrategias de marketing digital en el sector de la moda de lujo. Interacción y redes sociales como herramienta necesaria. Hipertext.net, n. 15, p. 17-27. DOI: $10.2436 / 20.8050 .01 .42$

Harmeling, C. M., Moffett, J. W., Arnold, M. J., \& Carlson, B. D. (2017). Toward a theory of customer engagement marketing. Journal of the Academy of marketing science, 45(3), 312-335.

Interactive Advertising Bureau (2019). Libro Blanco de Marketing de Infuencers. https://iabspain. es/estudio/libro-blanco-de-marketing-de-influencers/

Jiyoung, K. A., \& Ko, E. (2010). Impacts of luxury fashion brand's social media marketing on customer relationship and purchase intention. Journal of Global Fashion Marketing, 1(3): 164171. https://doi.org/10.1080/20932685.2010.10593068

Kering. (2019). Annual Results. R3 Worldwide, Kering Financial Document. https://www.kering. com/en/finance/ 
Khan, S. A. (2018). Instagram as a marketing tool for luxury brands. International Journal of Management, Business and Research, 8(2), 120-1226.

Kim, A. \& Ko, E. (2012). Do social media marketing activities enhance customer equity? An empirical study of luxury fashion brand. Journal of Business Research, 65(10), 1480-1486. https:// doi.org/10.1016/jjbusres.2011.10.014.

Krippendorff, K. (2004). Análisis de contenido: Una introducción a su metodología. Washington D.C: SAGE.

Larsson, A. O. (2017). The News User on Social Media. A comparative study of interacting with media organizations on Facebook and Instagram. Journalism Studies, 19(15), 2225-2242. https:// doi.org/10.1080/1461670X.2017.1332957

Launchmetrics (2019). Estatus del marketing de influencers. Un foco sobre el sector Moda, Lujo y Belleza. https://bit.ly/31NqZVC

Louis Vuitton Moet Hennessy. (2018). Annual report. https://www.lvmh.com/news-documents/ news/lvmh-publishes-2018-annual-report/

Markerly. (2017). Instagram Marketing: Does Influencer Size Matter? http://markerly.com/blog/ instagram-marketing-does-influencer-size-matter/

Martínez Navarro, G. (2017). Marketing y comunicación de moda. Madrid: ESIC Editorial.

Martínez-Sala, A. M., Segarra-Saavedra, J. y Monserrat-Gauchi, J. (2018). Los millennials como prosumers y adprosumers en las redes sociales corporativas. Cuadernos.info, (43), pp. 137-159. doi:10.7764/cdi.43.1335

Monserrat-Gauchi, J., \& Sabater-Quinto, F. (2017). Planificación estratégica de la comunicación en redes sociales. Barcelona: UOC.

OTB SpA Financial Reports and Brand results (2019). Annual Report. https://fashionbi.com/ companies/otb-spa

Padilla Castillo, G., \& Oliver González, A.B. (2018). "Instagramers" e “influencers”. El escaparate de la moda que eligen los jóvenes instagramers españoles. AdResearch, 18(18), 42-59.

Pedri Pereira, L. \& Schneider, T. (2017). «A influência da comunicação das marcas de moda de luxo nas redes sociais no valor percebido pelo consumidor.» dObra [s]: revista da Associação Brasileira de Estudos de Pesquisas em Moda10(22): 94-113. https://doi.org/10.26563/dobras.v10i22.637

Pedroni, M. (2016). Meso-celebrities, fashion and the media: How digital influencers struggle for visibility. Film, fashion \& consumption, 5(1): 103-121. https://doi.org/10.1386/ffc.5.1.103_1

Pérez-Curiel, C.\& Clavijo-Ferreira, L. (2017). Comunicación y Social Media en las Empresas de Moda. Prisma Social, (18), 226-258.

Pérez-Curiel ,C. \& Luque-Ortíz, S. (2018). El marketing de influencia en moda. Estudio del nuevo modelo de consumo en Instagram de los millennials universitarios. En: adComunica. Revista Científica de Estrategias, Tendencias e Innovación en Comunicación, $\mathrm{n}^{\circ}$ 15. Castellón:

Asociación para el Desarrollo de la Comunicación adComunica y Universitat Jaume I, 255281. http://dx.doi. org/10.6035/2174-0992.2018.15.13

Pérez-Curiel, C. \& Sanz-Marcos, P. (2019). Estrategia de marca, influencers y nuevos públicos en la comunicación de moda y lujo. Tendencia Gucci en Instagram. Prisma Social, (24), 1-24. 
Phan, M., Thomas, R., \& Heine, K. (2011). Social media and luxury brand management: The case of Burberry. Journal of Global Fashion Marketing, 2(4), 213-222. https://doi.org/10.1080/209326 85.2011.10593099.

Ramos-Serrano, M., \& Martínez García, M. A. (2016). Personal style bloggers: the most popular visual composition principles and themes on Instagram. Observatorio $\left(O B S^{*}\right), 10(2), 89-109$. http://dx.doi.org/10.15847/obsOBS1022016947

Ranking BrandZ (2015). Las 100 marcas más valiosas de 2015. http:// www.millwardbrown.com/ BrandZ/2015/Global/2015_BrandZ_Top100_Report.pdf

Rocamora, A. (2017), Mediatization and Digital Media in the Field of Fashion. Fashion Theory, 21(5), pp. 505-522.

Ruiz Cartagena, J.J. (2017). Millennials y redes sociales: estrategias para una comunicación de marca efectiva. Miguel Hernández Communication Journal, (8), pp. 347-367. https://bit. ly/3fReCfX

Sádaba, T., y SanMiguel, P. (2016), 'Fashion Blog's Engagement in the Customer Decision Making Process', in A. Vecchi y C. Buckley (eds.), Handbook of Research on Global Fashion Management and Merchandising, Hershey (PA): IGI Global, pp. 211-230.

Sanz-Marcos, P., Jiménez-Marín, G., \& Elías Zambrano, R. (2019). La incorporación de la figura del influencer en las campañas publicitarias: Consecuencias para las agencias de publicidad españolas. adComunica, (18), 63-86. http://dx.doi.org/10.6035/2174-0992.2019.18.5

Segarra-Saavedra, J., \& Hidalgo-Marí, T. (2018). Influencers, moda femenina e Instagram: el poder de prescripción en la era 2.0. Revista Mediterranea de Comunicación, 1(9), 313-325. https://doi.org/10.14198/MEDCOM2018.9.1.17

Shukla, P. (2011). Impact of interpersonal influences, brand origin and brand image on luxury purchase intentions: Measuring interfunctional interactions and a cross-national comparison. Journal of World Business, 46, 242-252. https://doi.org/10.1016/j.jwb.2010.11.002

Silverman, D. (2016). Qualitative research. Sage Publication Ltd.

Tsai, H.-T., Huang, H.C., \& Chiu, Y-L. (2012). Brand community participation in Taiwan: Examining the roles of individual-, group-, and relationship-level antecedents. Journal of Business Research, 65(5), 676-684. https://doi.org/10.1016/j.jbusres.2011.03.011

Van Nispen, J. (2015). Diccionario LID Marketing directo e interactivo. Madrid, España: LID Editorial Empresarial.

Vickers, J. S. and Renand, F. 2003. The marketing of luxury goods: An exploratory study. Marketing Review, 3(4): 459-478.

Vinader-Segura R, Vicente-Fernández, P y Gallego-Trijueque S. (2019). La comunicación de Moda en Youtube. Análisis del Género Haul en el caso de Dulceida. Prisma Social, (24), 78-98.

WOMMA. (2017). The WOMMA Guide to Influencer Marketing. 